\title{
Conservative Management of Ankyloglossia by Diode Laser: A Case Report
}

\author{
Namrata Gyawali, ${ }^{1}$ Sunanda Sundas, ${ }^{2}$ Barun Kumar Sah, ${ }^{3}$ Neha Dhakal ${ }^{4}$ \\ ${ }^{1}$ Post-graduate Resident, ${ }^{2}$ Associate Professor, ${ }^{3,4}$ Assistant Professor \\ ${ }^{1-4}$ Department of Pediatric and Preventive Dentistry, People's Dental College and Hospital, Sorakhutte, Kathmandu, Nepal.
}

\begin{abstract}
Ankyloglossia or tongue-tie is a congenital condition that results when the inferior lingual frenulum is too short and is attached to the tip of the tongue,limiting its normal movements. Ankyloglossia can lead to different problems such as difficulties in breastfeeding, speech impediments, poor oral hygiene, malocclusion, inability to deglutition, thus being an undesired problem in normal life activity. Among various methods of treatment of ankyloglossia, laser-assisted lingual frenotomy is the simplest, safest, and less traumatic with the most promising results. Here, a case of ankyloglossia and its management by frenotomy with diode laser is reported in a four-year-old female child. After performing partial frenectomy (frenotomy) using a diode laser of 980nm there was an immediate tongue protrusion and slight improvement of phonetics of the patient immediately and altogether improved after six months.
\end{abstract}

Keywords: Ankyloglossia, diode laser, frenotomy, tongue tie.

\section{INTRODUCTION}

Ankyloglossia or tongue-tie is a developmental anomaly of the tongue characterized by an abnormally short,thick lingual frenulum attaching to the tip of the tongue resulting in limitation of tongue movement. ${ }^{1}$ It occurs when a minor embryologic tissue remnant, the frenum, which usually undergoes apoptosis, persists resulting in restriction of normal tongue movement. ${ }^{2}$

Treatment options for tongue-tie include conventional surgical (scalpel) techniques (frenotomy, frenectomy, frenuloplasty) and lasers. Frenotomy is a simple incision of the frenulum. Surgery with diode laser provides excellent wound sterilization along with hemostasis and reduced postoperative pain. ${ }^{3}$

\section{Correspondence}

Dr. Namrata Gyawali

Post-graduate Resident,

Department of Pediatric and Preventive Dentistry,People's Dental College and Hospital,Sorakhutte,Kathmandu,Nepal. E-mail: namratagyawali@gmail.com

\section{Citation}

Gyawali N, Sundas S, Sah K B, Dhakal N. Conservative Management of Ankyloglossia by Diode Laser: A Case Report. J Nepal Assoc Pediatr Dent. 2021;2(1):28-31.

\section{CASE REPORT}

A four-year-old female reported to the Department of Pediatric and Preventive Dentistry, People's Dental College and Hospital,Sorakhutte,Kathmandu with a chief complaint of difficulty in speech and taking food. Medical history was non-contributory.

Extraoral examination showed no significant findings. On intraoral examination the patient had limited tongue mobility and prominent lingual frenum. When the patient was asked to protrude the tongue, slight blanching was seen on lingual aspect of the lower anterior teeth (Figure 1). The patient was unable to pronounce the words starting with letters "t", "d", "l", "th" and "s". The range of tongue

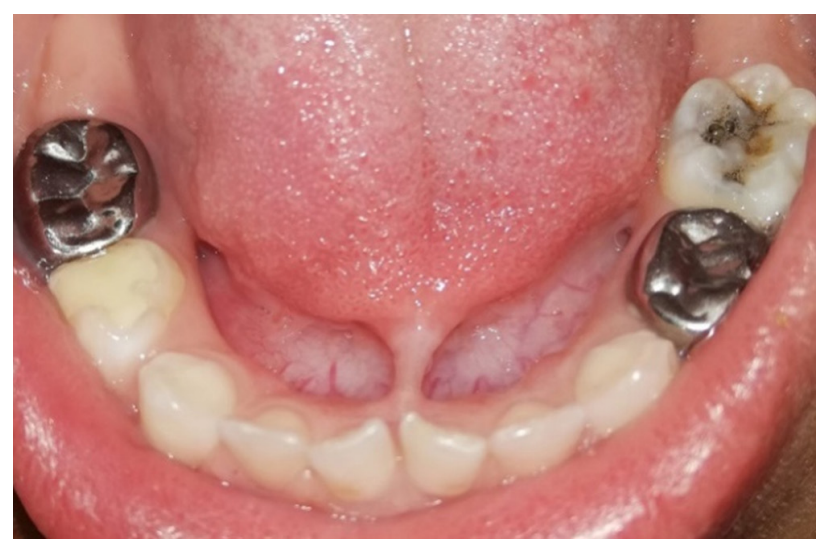

Figure 1. Pre-operative intraoral photograph. 
Table 1. As per Kotlow." Classification of Ankyloglossia based on "Free Tongue" Length.

\begin{tabular}{|c|c|c|}
\hline & Classification of Ankyloglossia & Range of free tongue \\
\hline Clinically acceptable,normal range of free tongue & $>16 \mathrm{~mm}$ \\
\hline Class I & Mild ankyloglossia & $12-16 \mathrm{~mm}$ \\
\hline Class II & Moderate ankyloglossia & $8-11 \mathrm{~mm}$ \\
\hline Class III & Severe ankyloglossia & $3-7 \mathrm{~mm}$ \\
\hline Class IV & Complete ankyloglossia & $<3 \mathrm{~mm}$ \\
\hline
\end{tabular}

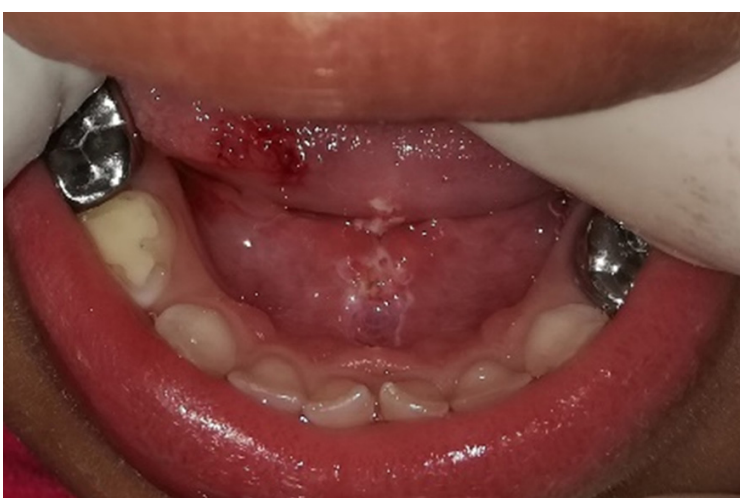

Figure 2. Immediate Post-operative intraoral photograph.

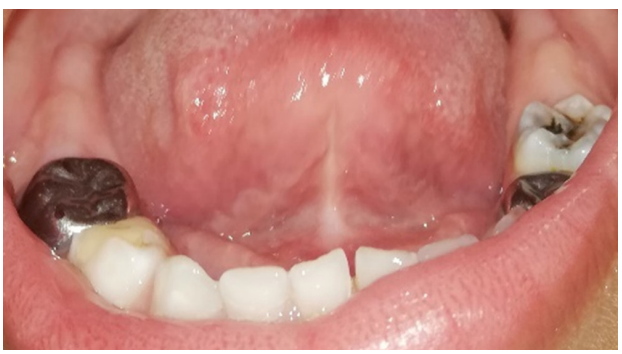

Figure 5. One week follow-up intraoral photograph.

movement was found to be nine $\mathrm{mm}$. It was diagnosed as Class II Ankyloglossia according to Kotlow assessment (Table. 1). ${ }^{1}$ Family history was not relevant.

After taking consent from patient's parents, a treatment plan of "light amplification by the stimulated emission of radiation" (LASER) guided partial frenectomy (frenotomy) was made. With the routine hematological investigations done, frenotomy was performed in which removal of part of lingual frenum was done with diode LASER (Sirona Dental Systems GmbH,Germany) having $980 \mathrm{~nm}$ wavelength at 1.5 Watt power in a continuous wave mode with flexible fiber optic quartz delivery system to make the tongue freely movable (Figure 2,3). The treatment was performed under local anesthesia (2\% Lidocaine with 1:200,000 adrenaline,Zen Pharma). The child and the operator were protected with appropriate eye glasses for the wavelength utilized. After performing

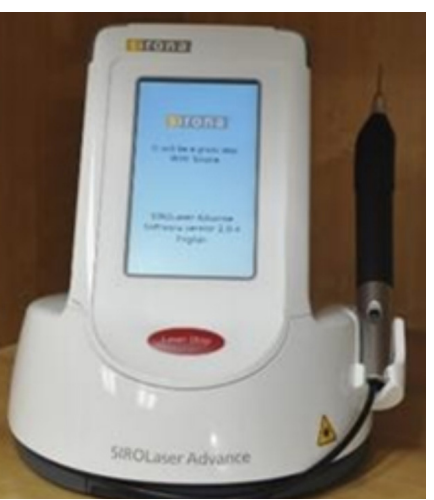

Figure 3. Sirona DiodeLASER.

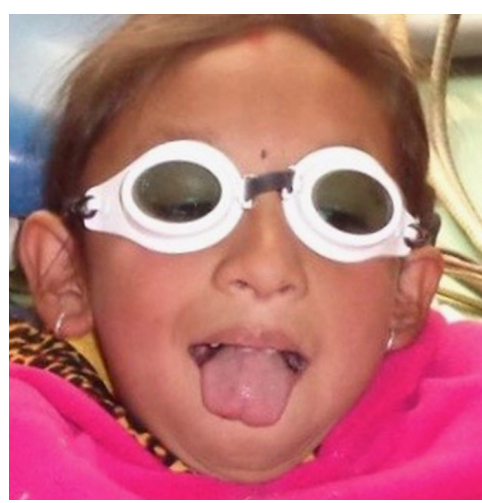

Figure 4. Immediate postoperative extraoral photograph.

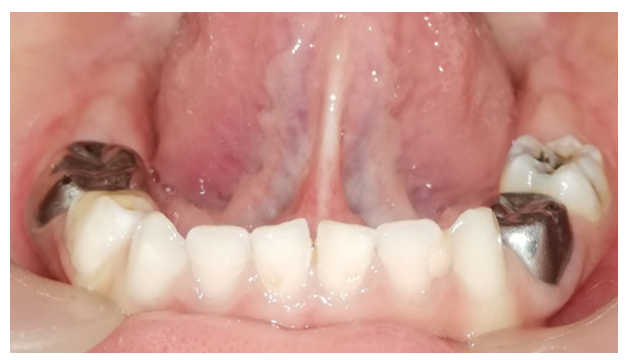

Figure 6. Six months follow-up photograph.

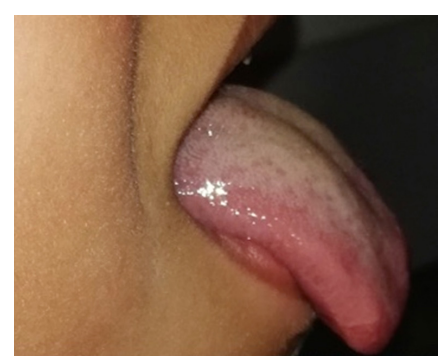

Figure 7. Six months followup photograph. a partial frenectomy, there was an immediate tongue protrusion and a freely movable tongue (Figure 4). The patient was kept on analgesics (Paracetamol 500mg and Ibuprofen $400 \mathrm{mg}$ ) to relieve pain for three days, and was also instructed to move the tongue slowly for postoperative exercise to avoid recurrence. The patient was referred to a speech therapist after frenotomy was done as parents were concerned about the altered speech of the child. The patient was followed up for six months with no evidence of recurrence and free mobility of tongue was present (Figure 5,6,7). The speech was found to be improved, and both patient and parents were satisfied.

\section{DISCUSSION}

Ankyloglossia is a congenital anomaly characterized by the attachment of the tongue to the floor of the mouth. ${ }^{1}$ It occurs due to failure in cellular degeneration leading 
to the longer anchorage between tongue and floor of the mouth. ${ }^{4}$ Ankyloglossia is a common finding in an otherwise normal child, or may be a part of certain rare syndromes such as X-linked cleft palate (OMIM 303400), Van der Woude syndrome (OMIM 119300), Orodigitofacial syndrome and Opitz syndrome. ${ }^{4}$ Literature reports the prevalence of ankyloglossia is higher in neonates $(1.72-10.7 \%)$ than in children, adolescents or adults (0.1$2.08 \%){ }^{5,6}$ In most of the patients it is asymptomatic, may spontaneously resolve, or affected individuals may learn to compensate for reduced lingual mobility, or may lead to various functional abnormalities that include abnormal speech, malocclusion, and inability to swallow the food which could entail difficulty in normal life activity of an individual. $^{7}$

Based on the distance of the insertion of the lingual frenum to the tip of the tongue,tongue-tie is classified from class I to class IV according to Kotlow's assessment (Table 1). ${ }^{1}$ Ankyloglossia, partial or complete causes specific speech disorders in certain individuals. It does not prevent or delay the onset of speech but interferes with articulation which was consistent with this case. A simple speech articulation test has been suggested if the elevation of the tongue tip is restricted, then the articulation of one or more of the tongue sounds- such as "t", "d", "l", "th" and "s" are not found to be accurate. ${ }^{8}$ In the present case also, the patient was unable to pronounce the word starting with these letters. Parents and patients should be educated regarding the long-term effects of ankyloglossia so that they can choose possible therapy.

The use of lasers for the treatment of ankyloglossia is one of the minimally invasive procedures. Advantages over conventional treatment are provision of bloodless operating field with no suture requirement and the shorter treatment duration which is preferable specially in case of pediatric patients. The conventional surgical technique is quiet invasive and poorly tolerated by patients unlike laser surgery which represents better option with regards to absence of intraoperative bleeding,reduced postoperative edema,excellent wound sterilization along with hemostasis and faster mucosal healing. Histologically laser wound has been found to have less number of myofibroblast, ${ }^{9}$ that leads to less wound contraction and scarring, ultimately resulting in improved healing with better postoperative perception of pain and function compared to scalpel technique. The settings used for lasers in infants and children should be lower than that normally used in adult patients due to differences in the thickness of the tissue. The oral tissues in infants and children are less fibrotic and thinner as compared with that of adult patients. In the present case, laser setting had been opted just for the removal of tissue. Laser-assisted lingual frenotomy is easy to perform with excellent precision, less discomfort, minimal or no bleeding due to sealing of capillaries by protein denaturation and stimulation of clotting factor VII production, shortened healing time with reduced postoperative bleeding and edema. ${ }^{10}$

Besides these, diode lasers have several other advantages when compared to conventional scalpel surgeries. They are compact and portable in design, with efficient and reliable benefits for use in soft tissue oral surgical procedures. In this case, $980 \mathrm{~nm}$ wavelength diode laser was used to perform frenotomy as it was available in the department. No complications and excellent patient satisfaction was found. Infiltration anesthesia was given along with topical anesthesia for the procedure. Most of the studies conducted on laser frenectomy have been performed using a topical spray with or without infiltration anesthesia. $^{10}$

In the present case, the patient had no intraoperative and postoperative complications in accordance with Aldelaimi $\mathrm{TN}^{10}$ study. But also in that study three patients experienced mild edema after the first day which subsided after third day. However, in the present case, no postoperative swelling,pain and edema were reported and good healing was reported after one week.

Postoperative exercise Active Wound Care (AWC) of the tongue is recommended after surgery to develop new muscle movements, particularly for elevation and protrusion, inside and outside of the mouth. ${ }^{7}$ It also increases the aesthetics of the tongue and lips. Moreover, it encourages the full range of tongue movement related to cleaning of the oral cavity,sweeping the insides of the cheeks,front and back of the teeth,and licking around both lips. A remarkable improvement in tongue movement and speech was seen in the present case after speech therapy and tongue exercise which was suggested to be performed in order to avoid reunion of the tongue and to allow free movement of the tongue. 


\section{CONGLUSIONS}

Tongue-tie or ankyloglossia affects several/many numbers of infants and children. Due to restricted tongue movement, it mainly causes difficulty in speech and may also cause improper chewing and swallowing of food which increases gastric distress and bloating. Therefore, intervention should be done as early as possible and it is important that even after treatment, accurate information and guidance be given to the parents so that appropriate revision could be done if required. Among various modalities of management of ankyloglossia, frenotomy technique with laser is considered one of the most conservative and simple procedure with good results.

Conflict of Interest: None

JNAPD

\section{REFERENGES}

Kotlow LA. Ankyloglossia (tongue-tie): a diagnostic and treatment quandary. Quintessence Int. 1999 Apr;30(4):259-62. [PubMed]

Knox I. Tongue-tie and frenotomy in the breastfeeding Newborn. NeoReviews 2010; 11(9): 513-9. [Full Text | DOI

Angiero F,Parma L,Crippa R,Benedicenti S. Diode laser $(808 \mathrm{~nm})$ applied to oral soft tissue lesions: a retrospective study to assess histopathological diagnosis and evaluate physical damage. Lasers Med Sci. 2012 Mar;27(2):383-8. [PubMed | DOI]

4. Verdine V A and Khan R. Management of ankyloglossia- Case reports. IOSR Journal of Dental and Medical Sciences 2013; 6(4):31-33. [Full Text]

5. Ballard JL,Auer CE,Khoury JC. Ankyloglossia: assessment,incidence,and effect of frenuloplasty on the breastfeeding dyad. Pediatrics. 2002 Nov;110(5):e63. [PubMed | Full Text | DOI]

6. Garcia Pola MJ,Gonzalez Garcia M,Garcia Martín JM,Gallas M,Seoane Leston J. A study of pathology associated with short lingual frenum. ASDC J Dent Child. 2002 Jan-Apr;69(1):59-62. [PubMed]

7. Lalakea ML,Messner AH. Ankyloglossia: the adolescent and adult perspective. Otolaryngol Head Neck Surg. 2003 May;128(5):746-52. [PubMed | DOI]

8. Kupietzky A,Botzer E. Ankyloglossia in the infant and young child: clinical suggestions for diagnosis and management. Pediatr Dent. 2005 Jan-Feb;27(1):40-6. [PubMed | Full Text]

9. Zeinoun T,Nammour S,Dourov N,Aftimos G,Luomanen M. Myofibroblasts in healing laser excision wounds. Lasers Surg Med. 2001;28(1):74-9. [리Med I DOI]

10. Aldelaimi TN,Mahmood AS. Laser-assisted frenectomy using 980nm diode laser. J Dent Oral Disord Ther. 2014;2(4):1-6. [ㅍ 11 Text | DOI] 